\title{
Continuous arch and rectangular loops for the correction of consistent and inconsistent load systems in extruded and tipped maxillary second molars
}

\author{
Ricardo Lima Shintcovsk, ${ }^{a}$ Lidia Parsekian Martins, ${ }^{b}$ Luegya Knop Shintcovsk, ${ }^{\mathrm{c}}$ Orlando Motohiro Tanaka, ${ }^{\mathrm{d}}$ \\ and Renato Parsekian Martins ${ }^{\mathrm{e}}$ \\ Araraquara, São Paulo, Salvador, Bahia, and Curitiba, Paraná, Brazil
}

\begin{abstract}
Introduction: The aim of this research was to compare the load systems produced by rectangular loops and continuous arches for the correction of extruded second molars with a mesial inclination (inconsistent system) and a distal inclination (consistent system). Methods: The maxillary first molar of an acrylic model of a patient, with passive brackets and tubes bonded, was connected to a 3-dimensional load cell of an orthodontic force tester, and the second molar was replaced by its respective tube bonded to a second load cell. The second molar tube was moved $2.5 \mathrm{~mm}$ occlusally and tipped $20^{\circ}$ mesially and distally, creating an inconsistent force system and a consistent force system. For each situation, ten $0.017 \times 0.025$-in beta-titanium, $8 \times 10-\mathrm{mm}$ rectangular loops were compared with 100.014 -in nickel-titanium continuous arches. The vertical forces- $F(z)$-and tipping moments- $M(x)$ - were compared using $4 t$ tests, at $5 \%$. Results: In the inconsistent group, the rectangular loop produced a larger $\mathrm{M}(\mathrm{x})$ in both molars: $2.11 \mathrm{~N} . \mathrm{mm}$ in the second molar compared with the $-0.15 \mathrm{~N} . \mathrm{mm}$ of the continuous arches. On the first molar, the rectangular loops produced -5.58 N.mm against -2.08 N.mm produced by the continuous arches. The $F(z)$ values produced at the second molar with each system were similar, whereas on the first molar they were different; the rectangular loops produced $0.41 \mathrm{~N}$, and continuous arches produced $0.53 \mathrm{~N}$. In the consistent group, the rectangular loops produced smaller $\mathrm{M}(\mathrm{x})$ values at the second molar $(-3.06 \mathrm{~N} . \mathrm{mm})$ than did the continuous arch $(-4.25 \mathrm{~N} . \mathrm{mm})(P=0.01)$, as well as a smaller $\mathrm{F}(\mathrm{z})$ value $(-0.52$ vs $-0.92 \mathrm{~N}$, respectively). At the first molar, the rectangular loops produced smaller $\mathrm{M}(\mathrm{x})$ values $(-2.32 \mathrm{~N} . \mathrm{mm})$ than did the continuous arch $(-4.18 \mathrm{~N} . \mathrm{mm})$, as well as a smaller $\mathrm{F}(\mathrm{z})$ value $(0.59 \mathrm{vs} 1.10 \mathrm{~N})$. Conclusions: In the inconsistent group, only the rectangular loop produced a system of force that could correct the second molar. In the consistent system, both group mechanics produced a system of force compatible with the correction of the second molar, but the continuous wire produced larger moments. Both groups showed a tendency for mesial crown tipping of the first molar. (Am J Orthod Dentofacial Orthop 2018;153:396-404)
\end{abstract}

\footnotetext{
aPrivate Practice, Salvador, Bahia, Brazil.

${ }^{\mathrm{b}}$ Department of Pediatrics and Orthodontics, Faculdade de Odontologia de Araraquara, Universidade Estadual Paulista, Araraquara, São Paulo, Brazil.

'Private Practice, Salvador, Bahia, Brazil.

${ }^{\mathrm{d}}$ Graduate dentistry program in orthodontics, Pontifícia Universidade Católica do Paraná, Curitiba, Paraná, Brazil.

ePrivate practice, Araraquara, São Paulo, Brazil; Program of Orthodontics, Faculdade de Odontologia de Araraquara, Universidade Estadual Paulista, Araraquara, São Paulo, Brazil.

All authors have completed and submitted the ICMJE Form for Disclosure of Potential Conflicts of Interest, and none were reported.

Address correspondence to: Renato Parsekian Martins, Rua Carlos Gomes, 2158, 14801320, Araraquara, São Paulo, Brazil; e-mail, dr_renatopmartins@hotmail. com.

Submitted, February 2017; revised and accepted, July 2017.

$0889-5406 / \$ 36.00$

(C) 2017 by the American Association of Orthodontists. All rights reserved.

https://doi.org/10.1016/j.ajodo.2017.07.021
}

$\mathrm{M}$ axillary permanent second molars frequently extrude when their antagonist teeth are lost or damaged, and their correction with continuous arch mechanics may not be adequate depending on the position of the brackets and tubes. ${ }^{1}$ When the force system (or load system) produced by a continuous arch is incompatible with the direction of the force or moment required for tooth correction, it is called an inconsistent load system, and a different strategy from the conventional continuous arch is required. ${ }^{2}$ Rectangular loops, ${ }^{3,4}$ temporary anchorage devices, ${ }^{5}$ or surgery ${ }^{6}$ may prove useful for correcting these orthodontic problems when the load system is inconsistent. However, there are situations when the direction of forces and moments produced by a straight wire match 


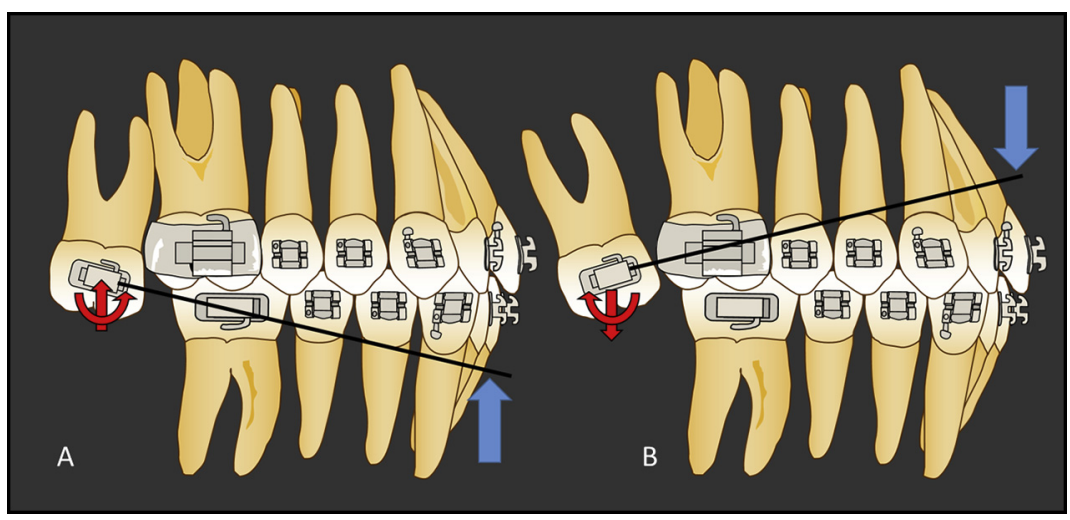

Fig 1. A, A maxillary second molar extruded with distal-crown tipping. Upon inserting a straight wire into the second molar tube (black line) and placing a force to engage it to the other brackets (blue arrow), an intrusive (desired) force with a mesial-crown tipping tendency (desired) is expected to occur. Because the estimated load system matches the one desired to correct the tooth, the load system is called consistent. B, A maxillary second molar extruded with mesial-crown tipping. Upon inserting a continuous arch into the second molar tube (black line) and placing a force to engage it to the other brackets (blue arrow), an extrusive force (unwanted) with a distal-crown tipping tendency (desired) is expected to occur. Since the estimated load system does not match the desired one to correct the second molar, the load system is termed inconsistent.

the ones desired for correction and are said to produce consistent load systems. ${ }^{2}$ In those situations, the correct bonding of the appliance and any leveling wire should be enough to correct the orthodontic problem, at least in theory.

When maxillary permanent second molars extrude, they may tip either crown mesially or crown distally due to their eruption pattern or dental migration. Depending on their position, the load system produced by a continuous arch may be estimated as consistent or inconsistent (Fig 1) according to a well-known orthodontic rationale. ${ }^{2}$ Therefore, the most appropriate solution for these 2 problems of mesial or distal tipping with extrusion might not be the same. When a second molar is extruded and tipped crown mesially, a rectangular loop is thought to be a more suitable solution than a continuous arch, which may not be able to produce the load system required for the correction. On the other hand, when an extruded second molar is tipped crown distally and the load system is consistent, a continuous arch may correct the second molar in a simpler manner.

However, these 2 strategies have never been objectively compared to determine whether one would be better than the other for consistent or inconsistent load systems in a specific clinical situation. A reliable way to compare the system of forces required for a clinical situation is with an orthodontic force tester, ${ }^{7}$ which is an orthodontic force measurement system composed of 2 three-dimensional load cells that can be adapted to any patient model to investigate different mechanics for the solution of a clinical problem..$^{8-17}$

Therefore, the aim of this study was to compare the 3-dimensional load system produced by a rectangular loop and a continuous arch in 2 situations of an extruded maxillary permanent second molar, one with mesial-crown tipping and one with distal-crown tipping (inconsistent and consistent systems of forces, respectively), to determine which approach would be the most appropriate for each orthodontic problem.

\section{MATERIAL AND METHODS}

A maxillary model of a patient was poured in acrylic resin and had 0.018-in MBT prescription brackets and tubes (Opal Orthodontics, Sandy, Utah) passively bonded with epoxy glue (JB Weld, Sulfur Springs, Tex), from second molar to second molar, using a $0.017 \times 0.025$-in stainless steel wire guide.

The model was secured to an orthodontic force tester custom-made table. One load cell (Multi-axis force/torque Nano 17; ATl Industrial Automation, Apex, NC) was attached to the left first molar (later released from the model), and the other one was connected to an articulated device that replaced the left second molar. The articulated device had a second molar tube bonded to it and was placed in the same position as the left second molar, after it was removed from the model (Fig 2, A). The distance between both molar tubes was $7 \mathrm{~mm}$, the same intertube distance before the removal of the second molar (Fig 2, B). 


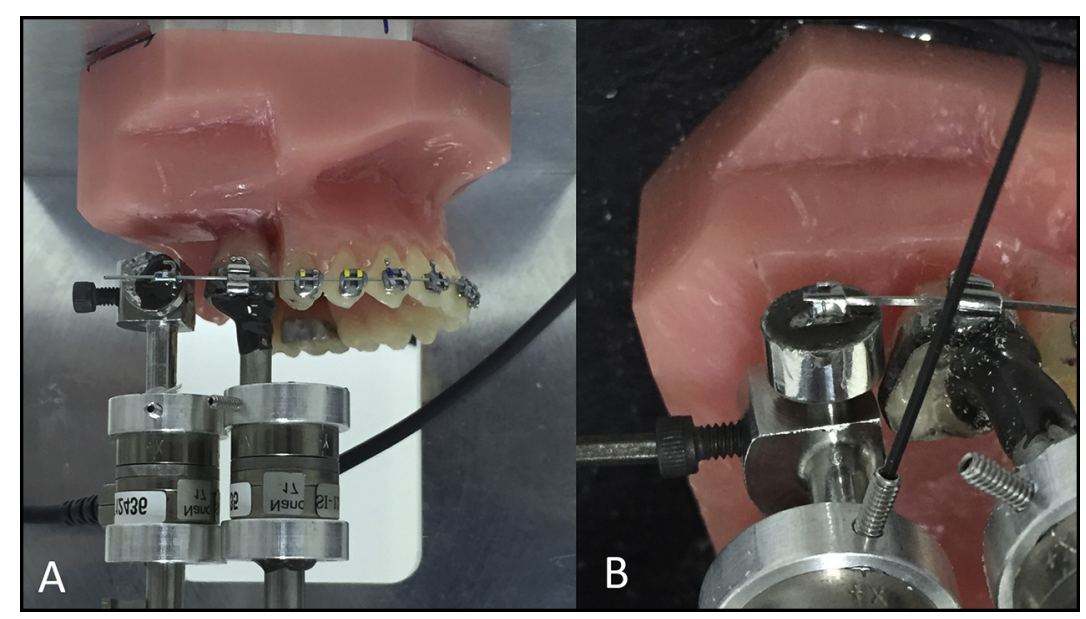

Fig 2. A, A maxillary acrylic model from a patient fixed to the orthodontic force tester. A load cell is attached to the left first molar, which will be separated from the model, whereas the second load cell is fixed to an accessory placed in the position of the second molar. A $0.017 \times 0.025$-in passive stainless steel wire was used as a guide to position the brackets and tubes. B, The custom-made accessory allowed a new second molar tube to be placed exactly in the same position as the original second molar tube. Its anglulation could also be modified. (Images were inverted vertically and horizontally for clarity.)

The second molar tube was moved $2.5 \mathrm{~mm}$ occlusally from its passive position using a precision rod and a digital dial (Mitutoyo, Aurora, III) adapted to the orthodontic force tester. The articulated device allowed the tube to be tipped $20^{\circ}$ in mesial and distal directions, enabling data from these 2 angulations to be obtained. Before the data were collected from each situation, tube angulations were assessed by Screen Protractor software (lconico, New York, NY) using a digital image of the setup. The orthodontic force tester custom software (Department of Mechanical Engineering, Perdue University, Indianapolis, Ind) allowed calibration of the load cells, which transferred the origins of the measurements from the center of the load cell to the center of each tube, regardless of the rotation or position of the load cells. The orientation of the reference grid for measurements was perpendicular ( $\mathrm{x}$ - and $\mathrm{z}$-axes) and parallel (y-axis) to the tubes.

The extruded second molar tube with a $20^{\circ}$ mesialcrown angulation was evaluated first, and the rectangular loop and the continuous arch mechanisms were compared. The load system was considered inconsistent in this group. A scaled digital image allowed the design of a template in the Loop Software (dHAL Orthodontic Software, Athens, Greece) for the bending of ten $8 \times 10-\mathrm{mm}$ rectangular passive loops from $0.017 \times 0.025$-in beta-titanium wires (TMA; Ormco, Glendora, Calif). The loop was designed with its box centralized to the tube of the second molar (Fig 3, A). The passivity of the loops was verified in the physical model using the measurements of forces and moments from the orthodontic force tester software. A second template for the preactivation of the loops was also made in the loop software as follows. First, the second molar bracket was repositioned virtually in the Loop software to its desired final position: ie, intruded and with its tipping corrected (a $2^{\circ}$ overcorrection was needed to ensure a parallel orientation of the wire angle of entry to the first molar tube). The loop was then activated, and the resulting active shape was frozen by an option of the Loop software (Fig 3, B), saved, and printed in real size. ${ }^{18}$

The passive loops were preactivated by bends and were stress relieved by trial activation as many times as needed, until the new preactivated shape matched the printed preactivation template. The center of the box of the loop was marked with a felt-tip pen to allow its position to be centralized with the second molar tube. The loops were inserted into the auxiliary tube of the first molar and into the second molar tube (Fig 4). Each loop was tested only once, and the orthodontic force tester software recorded the vertical forces (Fz) and tipping moments (Mx) of the second and first molars. Also, ten 0.014-in superelastic nickel-titanium wires (Highland Metals, Franklin, Ind) were tied to all brackets and tubes of the model with elastic ligatures (GAC International, Islandia, NY). (Fig 5, $A$ and $B$ ) to register the load system produced by continuous arch mechanics. The entire system was inserted into a box made of expanded rigid polystyrene plastic with an external hot-air source 


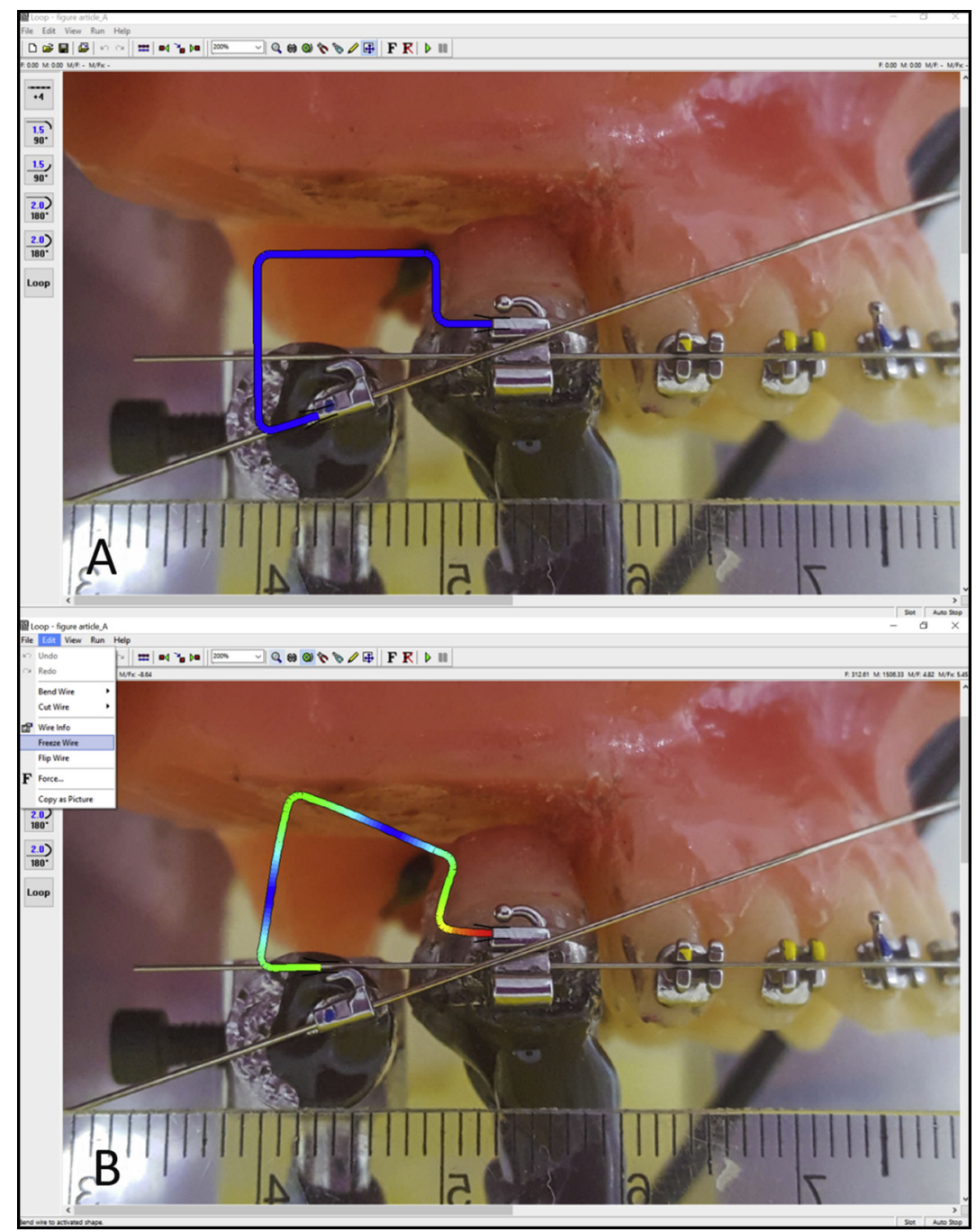

Fig 3. Loop Software images: A, the design of the passive rectangular loop. The dashed line shows the alignment of the center of the tube with the loop, and the arrow shows where a felt-tip pen mark was made on all loops. B, By placing the digital second molar tube in its desired corrected position (with a $2^{\circ}$ overcorrection) activating the loop and freezing its new shape, a preactivation shape was designed. Both images were printed in a scale to serve as templates. (The images were inverted vertically and horizontally.)

controlled by a digital thermometer maintaining the temperature at $37^{\circ} \mathrm{C} \pm 1^{\circ} \mathrm{C}$.

A second clinical setup was used to compare the same mechanics by altering the $20^{\circ}$ of mesial-crown tipping to distal-crown tipping, maintaining the vertical position of the tube. This second situation was assumed to produce a consistent load system. Ten passive rectangular loops in this new tube position were hand-bent with the same protocol as in the inconsistent situation (Fig 5, C) that included the design of 2 new individualized templates (for passive shape and preactivation).
The same 10 nickel-titanium wires from the same batch used in the inconsistent situation were side-flipped and similarly tied to all brackets and tubes of the model to collect the $\mathrm{F}(\mathrm{z})$ and $\mathrm{M}(\mathrm{x})$ values produced by the continuous arch (Fig 5, D)

The data collected from the 2 groups were normally distributed and were compared using 4 independent $t$ tests, with a significance level of 5\%, to detect differences between the $\mathrm{F}(\mathrm{z})$ and $\mathrm{M}(\mathrm{x})$ produced by the rectangular loops and continuous arch mechanics for the first and second molars in each situation, inconsistent and consistent. 


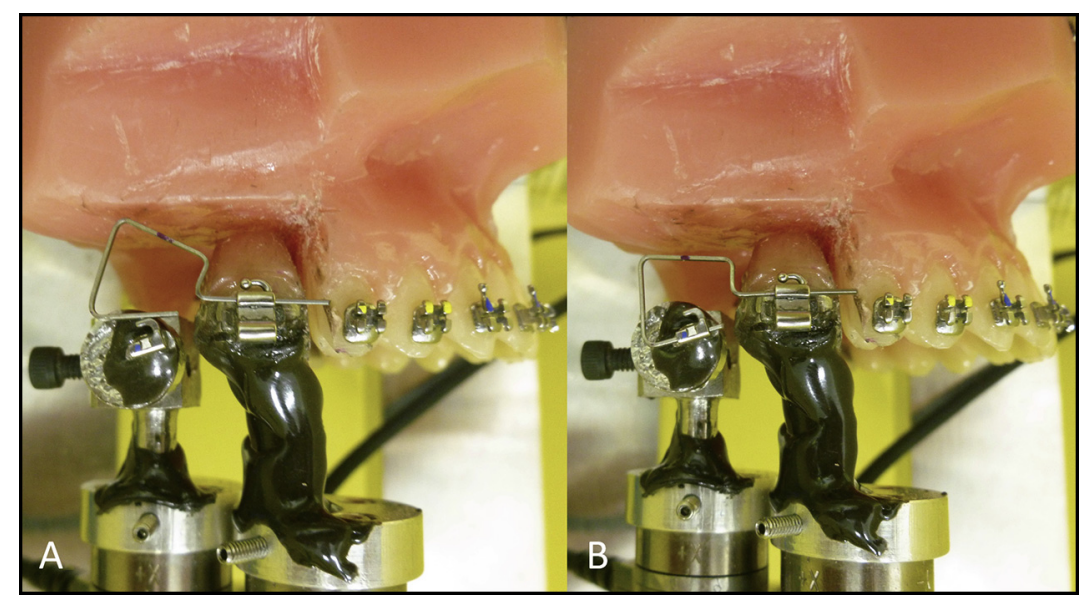

Fig 4. A, Preactivated rectangular loop; B, activated rectangular loop engaged to the second molar tube. (The images were inverted vertically and horizontally.)

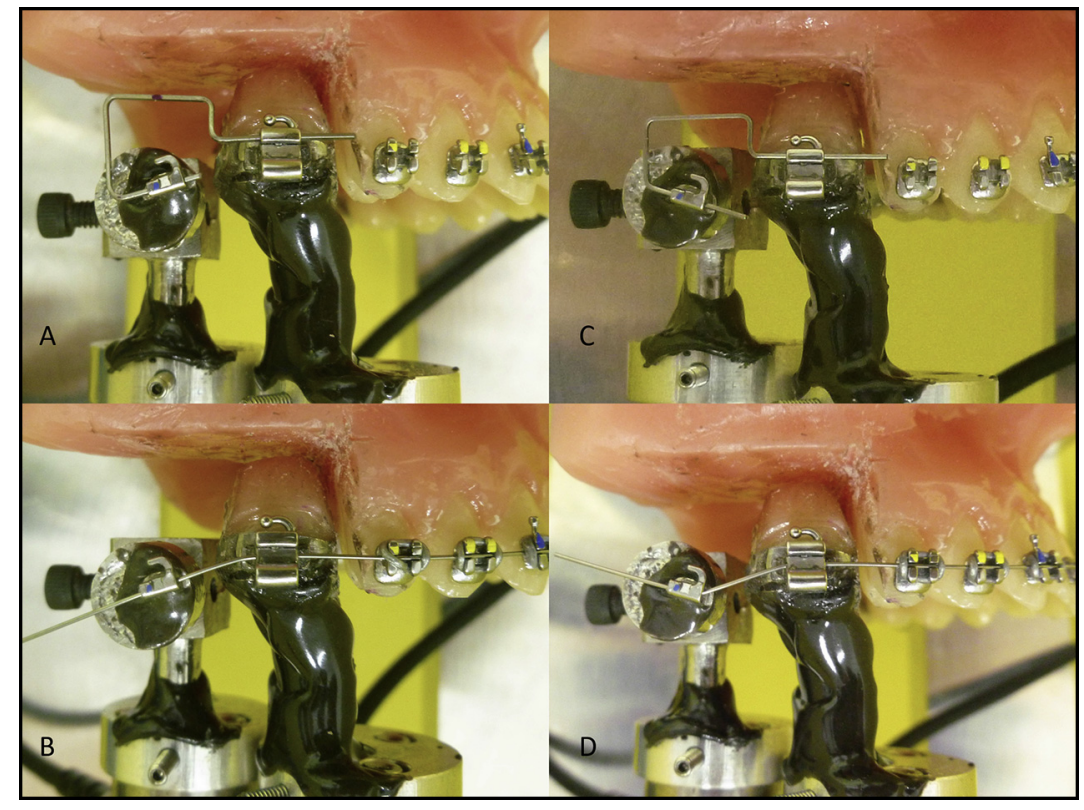

Fig 5. A, Rectangular loop engaged in the inconsistent group; B, 0.014-in nickel-titanium wire engaged in the inconsistent group; $\mathbf{C}$, rectangular loop engaged in the consistent group; D, 0.014-in nickeltitanium wire engaged in the consistent group. (The images were inverted vertically and horizontally.)

\section{RESULTS}

In the inconsistent simulation, the $\mathrm{M}(\mathrm{x})$ values produced were different $(P<0.001)$. In the second molar tube, the loops produced an $\mathrm{M}(\mathrm{x})$ value of $2.11 \mathrm{~N} . \mathrm{mm}$, whereas the continuous arch produced -0.15 N.mm (Table 1). In the first molar tube, the loops produced -5.58 N.mm, and the continuous arch produced $-2.08 \mathrm{~N} . \mathrm{mm}$. No differences were found for the F(z) produced in the second molars $(P=0.118)$, but they were different for the first molars $(P<0.001)$, where the loops produced $0.41 \mathrm{~N}$ against $0.53 \mathrm{~N}$ produced by the continuous arch (Table 1).

In the consistent situation, the loops produced smaller $\mathrm{M}(\mathrm{x})$ values $(-3.06 \mathrm{~N} . \mathrm{mm})$ than the continuous arch $(-4.25 \mathrm{~N} . \mathrm{mm})$ (Table 11) in the second molars as well as smaller $\mathrm{F}(\mathrm{z})$ values $(-0.52$ and $-0.92 \mathrm{~N}$, respectively). In the first molars, the loops also produced smaller $\mathrm{M}(\mathrm{x})(-2.32 \mathrm{~N} . \mathrm{mm})$ and $\mathrm{F}(\mathrm{z})(0.59 \mathrm{~N})$ values 
Table I. Average values of vertical force $\mathrm{F}(\mathrm{z})$ and tipping moments $\mathrm{M}(\mathrm{x})$, with standard deviations in parenthesis, measured at the tubes of the second and first molars in the inconsistent force system (extruded second molar with mesial-crown tipping)

\begin{tabular}{|c|c|c|c|}
\hline & Group & $M x(N . m m)$ & $F Z(N)$ \\
\hline \multirow{3}{*}{ Second molar } & Rectangular loop & $2.11(0.45)$ & $-0.41(0.11)$ \\
\hline & $\begin{array}{l}0.014-\text { in } \\
\text { nickel-titanium wire }\end{array}$ & $-0.15(0.06)$ & $-0.35(0.02)$ \\
\hline & Significance & $P<0.001$ & $P=0.118$ \\
\hline \multirow[t]{3}{*}{ First molar } & Rectangular loop & $-5.58(1.34)$ & $0.41(0.11)$ \\
\hline & $\begin{array}{l}0.014 \text {-in } \\
\text { nickel-titanium wire }\end{array}$ & $-2.08(0.55)$ & $0.53(0.01)$ \\
\hline & Significance & $P<0.001$ & $P=0.007$ \\
\hline
\end{tabular}

Positive values depict extrusive forces and crown-distal tipping tendency. The values given in Newtons and Newtons.mm can be converted to gram-force and gram-force.mm by multiplying them by 102 .

Table II. Average values of vertical force $F(z)$ and tipping moments $\mathrm{M}(\mathrm{x})$, with standard deviations in parenthesis, measured at the tubes of the second and first molars in the consistent force system (extruded second molar with distal crown tipping)

\begin{tabular}{|c|c|c|c|}
\hline & Group & $M x(N . m m)$ & $F z(N)$ \\
\hline \multirow{3}{*}{ Second molars } & Rectangular loop & $-3.06(1.25)$ & $-0.52(0.09)$ \\
\hline & $\begin{array}{l}0.014-i n \\
\text { nickel-titanium wire }\end{array}$ & $-4.25(0.16)$ & $-0.92(0.03)$ \\
\hline & Significance & $P=0.015$ & $P<0.001$ \\
\hline \multirow[t]{3}{*}{ First molars } & Rectangular loop & $-2.32(1.41)$ & $0.59(0.10)$ \\
\hline & $\begin{array}{l}0.014-\text { in } \\
\text { nickel-titanium wire }\end{array}$ & $-4.18(0.39)$ & $1.10(0.03)$ \\
\hline & Significance & $P=0.002$ & $P<0.001$ \\
\hline
\end{tabular}

Positive values depict extrusive forces and crown-distal tipping tendency. The values given in Newtons and Newtons.mm can be converted to gram-force and gram-force.mm by multiplying them by 102 .

compared with the continuous arch mechanics $(-4.18 \mathrm{~N} . \mathrm{mm}$ and $1.10 \mathrm{~N})$.

\section{DISCUSSION}

When the maxillary second molar was tipped crownmesially, the load system ( $\mathrm{Fz}$ and $\mathrm{Mx}$ ) produced by the continuous arch was inconsistent because it produced an undesired mesial-crown tipping tendency in the second molar tube along with the desired intrusive force. Therefore, a continuous nickel-titanium wire would not correct the second molar. Although the load system was expected to be inconsistent, the predicted directions of the forces and moments were incorrect. In the second molar tube, an extrusive force and a distal crown tipping tendency were expected (Fig 1, B) rather than an

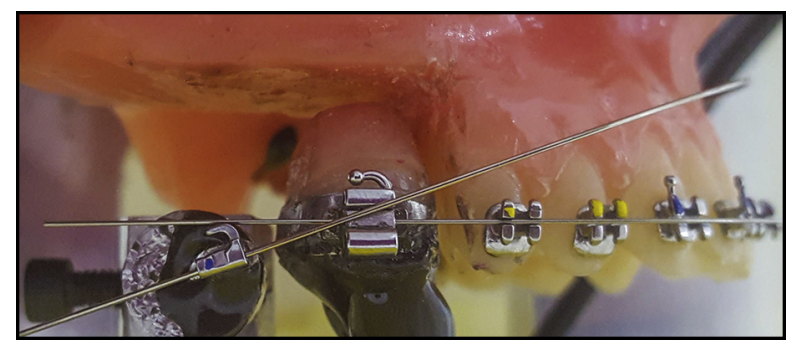

Fig 6. Inconsistent load system tested in this investigation. The intersection of the 2 passive wires points to a larger moment acting on the first molar tube because it is closer to the intersection of the wires. Thus, a passive wire inserted in the first molar tube should be used to estimate the direction of the vertical forces of equilibrium, rather than a wire inserted into the second molar tube.

intrusive force and crown-mesial tipping. This can be explained by the relative position between the tubes, ${ }^{1}$ where the moment ratio $(0.07)$ between the second molar $(-0.15 \mathrm{Nmm})$ and first molar $(-2.08 \mathrm{Nmm})$ points closely to Class IV geometry (when the ratio would be 0) (Table 1). An incorrect estimation of the direction of vertical forces (Fig 1, B) occurred because the wrong passive wire was used for that estimation. An appropriate estimation of the vertical forces produced between 2 tubes can be easily done by inserting a piece of straight wire into each tube and observing where those wires intersect (Fig 6). The tube closest to the intersection will be the one subjected to the greater moment and will dictate the direction of the equilibrium forces in each tube. ${ }^{19}$ The estimation of vertical forces (Fig 1, A) should have been done with the wire inserted into the first molar tube, rather than inserted into the second molar, because it was closer to the intersection of the 2 wires (Fig 6).

The rectangular loop produced a different load system than the continuous arch in the inconsistent situation. The loop produced an intrusive force and a distal-crown tipping tendency, which was required for the correction of the second molar. It appears that the rectangular loop is the only alternative to correct the problem compared with the continuous arch. Other loops, such as the Lloop ${ }^{20-22}$ or the T- loop, ${ }^{21,22}$ would produce similar load systems to the continuous arch and would not correct the second molar. Those loops cannot disassociate the intensity and direction of the moment produced from its vertical activation, which dictates them. The rectangular loop, due to its design, has the ability to disassociate the direction of moments produced from the direction of vertical activation, as has already been demonstrated in nonpreactivated rectangular loops using a 2-bracket system. ${ }^{22-24}$ Moreover, the possibility of individually preactivating the loops, as done in this study, may allow 
shorter loops to be used when a patient has a shallow vestibule.

The load system that allows the correction of the second molar given by the rectangular loop does not come without the side effect of a mesial inclination tendency on the maxillary first molar tube. This is because the positive moment that would correct the tipping of the second molar needs to be counterbalanced. That holds true even in the load system given by the continuous arch, which will not correct the second molar. The orthodontic literature has extensively explored the principles of equilibrium in situations between 2 brackets, similar to the one demonstrated here, with unleveled brackets and a straight wire ${ }^{1,25}$ or with active bends in leveled brackets. ${ }^{26,27}$ The use of the loop without proper control of the moments produced in the first molar tube is not advisable because of the side effects that may result from this movement, such as an undesired change of the anteroposterior relationship. Therefore, the use of a transpalatal bar for the distribution of this moment to more teeth, ${ }^{4}$ or even Class 11 elastics with a cursor, applying a distal force directly to the first molar, is recommended. In this latter example, even a light force $(1 \mathrm{~N}$, which is approximately $102 \mathrm{gf}$ ) placed below the molars' axis of resistance (about 6-8 $\mathrm{mm}$ ) could produce a crown distal moment high enough (6-8 N.mm) to counteract the crown mesial tipping moment produced by the loop.

In the consistent situation, where the extruded maxillary second molar had distal-crown tipping, the loop and the continuous arch operated similarly. Both systems showed a load system that could produce the desired correction: ie, an intrusive force with a crown-mesial tipping tendency. This result was not unexpected, for it is well known in orthodontics that consistent load systems only require a resilient wire to produce the required result. ${ }^{2}$ However, the larger moment produced by the continuous arch in the second molar tube was unexpected. This may allow greater efficiency for the correction of the second molar in the consistent situation, possibly resulting in a faster correction of its tipping, in a simpler and less laborious way. Like the inconsistent load system, moments of high magnitude were recorded on the first molar tube, producing a mesial-crown tipping tendency, in both mechanics. As mentioned, this high tipping moment of the first molars needs to be controlled to prevent side effects.

The intrusive forces produced in the inconsistent and consistent groups were different, except for those acting on the second molar in the inconsistent group. In general, the vertical forces produced in the consistent group were greater, even though the second molar tube was displaced the same $(2.5 \mathrm{~mm})$ in both situations. This possibly occurred because of the larger deflection of the wire

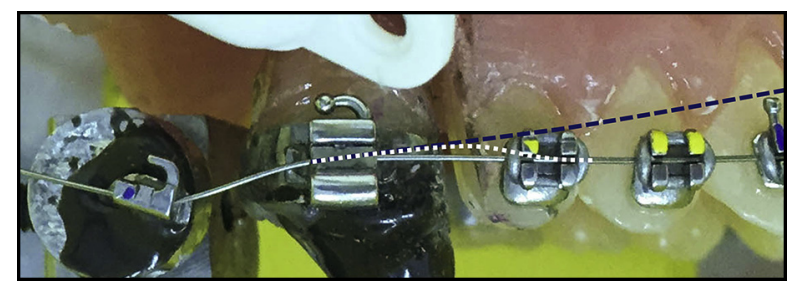

Fig 7. Image of continuous mechanics tested. The black line shows the estimated deflection of the archwire if it is not tied to the brackets; the white line shows the deflection (exaggerated for comprehension) of the wire when it is tied. This deflection is too small to be perceived by the naked eye, but it is enough to produce the forces described in this investigation.

interproximally between both molar tubes in the consistent situation compared with the inconsistent situation (Fig 5, $B$ and $D$ ), which produced larger forces and moments. This effect can be explained by the relative angular position, or geometry, between the tubes as has already been shown: equilibrium of different angular positions between 2 brackets, even when they are leveled, can produce different vertical forces. ${ }^{1}$ Different from the nearly Class IV geometry produced by the continuous arch in the inconsistent system (Table 1), the ratio between the moments produced (1.02) by the second and first molars (Table 11) was close to Class 1 geometry in the latter situation, with greater vertical forces to equilibrate the system.

Another unexpected result was the difference between the vertical forces produced in both molars $(-0.35$ and $0.53 \mathrm{~N})$ when the continuous arch was tested, something that did not occur with the loops. Although this may seem to be a load cell error, because forces of the same intensity were expected, it can be explained by the wire deflection. The angle of entry of the wire in the mesial extremity of the first molar tube produces a supplemental extrusive force on both molars, reducing the net intrusive force on the second molar, while increasing it on the first (Fig 7). The classic articles that dealt with continuous arch mechanics only used a 2-bracket system ${ }^{1,26,27}$ and did not detect this effect. When full multibracket appliances were investigated, vertical forces in the opposite direction to what was expected could be detected on brackets far from the tooth to be corrected, as we observed. ${ }^{28-30}$

The continuous arch produced greater vertical forces. They depend on 2 factors: the relative position of the tubes ${ }^{1}$ and the modulus of elasticity of the wire used, ${ }^{31}$ leaving the orthodontist with few options to adjust the force, if desired. On the rectangular loop, however, the force can be changed by adjusting the vertical activation regardless of the moments produced. Its disassociation 
ability enables the moments produced to be varied independently of vertical activation, and one can be increased without proportionally influencing the other; this is different from the continuous arch, where the moment and force are produced proportionally. ${ }^{22}$

In this simulation, we used 0.018-in slot brackets for the evaluation of both mechanics, a 0.014-in nickeltitanium wire, and a $0.017 \times 0.025$-in beta-titanium rectangular loop. Although the continuous archwire might be the first choice of initial wire for most orthodontists, not all use 0.018-in brackets. Whereas most auxiliary tubes in the first molar tubes are $0.018 \mathrm{in}$, even if the main slot is $0.022 \mathrm{in}$, some clinicians might use 0.022 -in tubes in the second molars. We believe that this will not change the load system in both mechanics because the calculated second order clearances will be only slightly larger $\left(1.76^{\circ}\right)$ on the second molar tube, due to its length (about $3.3 \mathrm{~mm}$ ). ${ }^{32}$

The results of this study describe the immediate load system produced by 2 mechanics, as correction, or worsening, of the malpositioned teeth occurs, the geometry between the brackets alters, changing the whole load system. Whereas finite element models have been used to estimate changes of the load system that will occur with tooth movement, it is still unknown whether those estimates will match the biologic responses; they should be further studied. ${ }^{33-36}$ Nonetheless, in that regard, rectangular loops allow individual reactivation and adjustment to the new position of the teeth as the patient returns for adjustments, whereas in the continuous arch, the load system will still be dictated by the brackets and out of the orthodontist's control.

\section{CONCLUSIONS}

According to the 2 simulations performed in this investigation, when the second molar tube was extruded $2.5 \mathrm{~mm}$ and tipped crown-mesially or distally by $20^{\circ}$ creating, respectively, an inconsistent or a consistent load system:

1. In the inconsistent system, the rectangular loop produced a load system compatible with the correction of the second molar, producing intrusion and a distal-crown tipping tendency, whereas the continuous arch could not.

2. In the consistent system, both mechanics produced a load system compatible with the correction required, but the continuous arch produced a larger tipping moment favoring the correction.

3. In both load systems, the mesial-crown tipping tendency on the first molar tube was detected as a side effect.

\section{REFERENCES}

1. Burstone CJ, Koenig HA. Force systems from an ideal arch. Am J Orthod 1974;65:270-89.

2. Marcotte MR. Biomechanics in orthodontics. Philadelphia: BC Decker; 1990.

3. Cacciafesta V, Melsen B. The rectangular loop: biomechanical principles and clinical applications in three dimensional control of single-tooth discrepancies. Prog Orthod 1999;1:23-36.

4. Crismani AG, Freudenthaler JW, Bernhart T, Hofshneider UB, Kole EG. Rectangular loops in inconsistent force systems. J Orofac Orthop 2002;63:105-12.

5. Chang YJ, Lee HS, Chun YS. Microscrew anchorage for molar intrusion. J Clin Orthod 2004;38:325-30.

6. Schoeman R, Subramanian L. The use of orthognathic surgery to facilitate implant placement: a case report. Int J Oral Maxillofac Implants 1996;11:682-4.

7. Chen J. Apparatus and method for measuring orthodontic force applied by an orthodontic appliance. United States patent number 6.120.287.

8. Yadav S, Chen J, Upadhyay M, Roberts E, Nanda R. Three-dimensional quantification of the force system involved in a palatally impacted canine using a cantilever spring design. Orthodontics (Chic.) 2012;13:22-33.

9. Viecilli RF, Chen J, Katona TR, Roberts WE. Force system generated by an adjustable molar root movement mechanism. Am J Orthod Dentofacial Orthop 2009;135:165-73.

10. Yadav S, Chen J, Upadhyay M, Jiang F, Roberts WE. Comparison of the force systems of 3 appliances on palatally impacted canines. Am J Orthod Dentofacial Orthop 2011;139:206-13.

11. Gajda S, Chen J. Comparison of three-dimensional orthodontic load systems of different commercial archwires for space closure. Angle Orthod 2012;82:333-9.

12. Mittal N, Xia Z, Chen J, Stewart KT, Liu SS. Three-dimensional quantification of pretorqued nickel-titanium wires in edgewise and prescription brackets. Angle Orthod 2013;83:484-90.

13. Xia Z, Chen J, Jiangc F, Li S, Viecilli RF, Liu SY. Load system of segmental T-loops for canine retraction. Am J Orthod Dentofacial Orthop 2013;144:548-56.

14. Almeida L, Ribeiro A, Parsekian Martins R, Viecilli R, Parsekian Martins L. Nickel titanium T-loop wire dimensions for en masse retraction. Angle Orthod 2016;86:810-7.

15. Katona TR, 1sikbay SC, Chen J. Effects of first- and second-order gable bends on the orthodontic load systems produced by $\mathrm{T}$ loop archwires. Angle Orthod 2014;84:350-7.

16. Kroczek C, Kula K, Stewart K, Baldwin J, Fu T, Chen J. Comparison of the orthodontic load systems created with elastomeric power chain to close extraction spaces on different rectangular archwires. Am J Orthod Dentofacial Orthop 2012;141:262-8.

17. Chen J, lsikbay SC, Brizendine EJ. Quantification of threedimensional orthodontic force systems of T-loop archwires. Angle Orthod 2010;80:566-70.

18. Halazonetis DJ. Understanding orthodontic loop preactivation. Am J Orthod Dentofacial Orthop 1998;113:237-41.

19. Isaacson RJ, Lindauer SJ, Davidovitch M. The ground ruler for arch wire design. Semin Orthod 1995;1:3-11.

20. Raboud D, Faulkner G, Lipsett B, Haberstock D. Three-dimensional force systems from vertically activated orthodontic loops. Am J Orthod Dentofacial Orthop 2001;119:21-9.

21. Menghi C, Planert J, Melsen B. 3-D experimental identification of force systems from orthodontic loops activated for first order corrections. Angle Orthod 1999;69:49-57. 
22. Vanderby R Jr, Burstone CJ, Solonche DJ, Ratches JA. Experimentally determined force systems from vertically activated orthodontic loops. Angle Orthod 1977;47:272-9.

23. DeFranco JC, Koenig HA, Burstone CJ. Three-dimensional large displacement analysis of orthodontic appliances. J Biomech 1976;9:793-801.

24. Koenig HA, Vanderby R, Solonche DJ, Burstone CJ. Force systems from orthodontic appliances: an analytical and experimental comparison. J Biomech Eng 1980;102:294-300.

25. Lindauer SJ, Isaacson RJ, Britto D. Three dimensional force systems from activated orthodontic appliances. Semin Orthod 2001; 7:207-14.

26. Ronay F, Kleinert W, Melsen B, Burstone CJ. Force system developed by $\mathrm{V}$ bends in an elastic orthodontic wire. Am J Orthod Dentofacial Orthop 1989;96:295-301.

27. Burstone CJ, Koenig HA. Creative wire bending-the force system from step and V bends. Am J Orthod Dentofacial Orthop 1988;93:59-67.

28. Major PW, Toogood RW, Badawi HM, Carey JP, Seru S. Effect of wire size on maxillary arch force/couple systems for a simulated high canine malocclusion. J Orthod 2014;41:285-91.

29. Fok J, Toogood RW, Badawi H, Carey JP, Major PW. Analysis of maxillary arch force/couple systems for a simulated high canine malocclusion: part 1. Passive ligation. Angle Orthod 2011;81:953-9.
30. Fok J, Toogood RW, Badawi H, Carey JP, Major PW. Analysis of maxillary arch force/couple systems for a simulated high canine malocclusion: part 2. Elastic ligation. Angle Orthod 2011;81:960-5.

31. Burstone CJ. Variable-modulus orthodontics. Am J Orthod 1981; 80:1-16.

32. Thurow RC. Edgewise orthodontics. 1slandia, NY: GAC International; 2001.

33. Kojima Y, Fukui $\mathrm{H}$. Numerical simulations of canine retraction with T-loop springs based on the updated moment-to-force ratio. Eur J Orthod 2012;34:10-8.

34. Roberts WE, Viecilli RF, Chang C, Katona TR, Paydar NH. Biology of biomechanics: finite element analysis of a statically determinate system to rotate the occlusal plane for correction of a skeletal Class 111 open-bite malocclusion. Am J Orthod Dentofacial Orthop 2015; 148:943-55.

35. Kojima Y, Fukui H. A finite element simulation of nickel-titanium movement, orthodontic movement, and the centre of resistance of the maxillary teeth connected with an archwire. Eur J Orthod 2014;36:255-61.

36. Kojima Y, Kawamura J, Fukui H. Finite element analysis of the effect of force directions on tooth movement in extraction space closure with miniscrew sliding mechanics. Am J Orthod Dentofacial Orthop 2012;142:501-8. 